\title{
Influence of the Practicum Experience on Student Teachers' Beliefs about their Role in EFL Classrooms
}

\author{
Youmen Chaaban \\ Azm University \\ Tripoli, Lebanon \\ Xiangyun Du \\ Qatar University \\ Doha, Qatar \\ Maha Ellili-Cherif \\ Qatar University \\ Doha, Qatar
}

\begin{abstract}
As worldwide educational reforms link educational outcomes with teacher performance, teachers are increasingly pressured to adopt several roles that reflect these new demands. Thus, the purpose of the study was to investigate student teachers' perceptions of their roles and whether these beliefs underwent certain changes during the practicum experience. It also explored the factors within the socio-cultural context that may have influenced the development of their beliefs. A qualitative research methodology was employed, which involved the collection of empirical data from multiple sources including pre- and postinterviews, weekly journals, and mid- and post-reflective essays. The results revealed the intricate nature of student teachers' beliefs about their roles and the processes of belief change. Despite the apparent flexibility of these beliefs, the results revealed the divergence between the student teachers' anticipated roles and their actual roles. To facilitate student teachers' belief change towards the goals of the teacher preparation program as well as those they had initially anticipated for themselves, several recommendations include the necessity of establishing closer partnerships between universities and schools, the exposure to multiple social learning activities, a careful consideration for student teachers' procedural concerns, and the attention to the subtle power relationships that play out during the practicum experience.
\end{abstract}

Keywords: student teachers' beliefs; teacher roles; practicum experience; teacher preparation; Qatari context. 


\section{Introduction}

Worldwide educational reforms introducing new trends in teaching and learning, revised standards and tests, innovative curricula, and redesigned schools have contributed to a reconceptualization of teachers' roles (DarlingHammond, 2010; Garrido \& Alvarez, 2006). Language teachers are required to keep up with policy reforms by extending their traditional roles as knowledge transmitters to fit new requirements (Wang \& Du, 2016). For example, Morrison and Navarro (2012) propose a role shift from language teacher to learning advisor who advocates learner autonomy and directs students into acquiring effective learning habits. As such, a teacher's role has a direct influence upon students' active participation and collaborative learning opportunities (Ahonen, Pyhältö, Pietarinen, \& Soini 2014).

These educational reforms have further challenged teacher preparation programs to prepare future teachers who are capable of fulfilling multiple roles. Such has been the case in the Qatari educational context. Public interest in reforming schools and improving educational outcomes has remained at an alltime high since 2007 when Qatar's reform initiative, Education for a New Era, was published. The document contributed to challenging the traditional role of teachers as knowledge transmitters and emphasized the need for high-quality teachers capable of performing multiple roles, such as facilitators, guides, and coaches, to improve student learning (Brewer et al., 2007). To this end, the only teacher preparation institution in the country has a significant role to play in sharing the responsibility for the success of the reform.

Essentially, the type of teacher preparation required is one that acknowledges student teachers' deeply grounded beliefs as significant factors influencing their practices ( $\mathrm{Ng}$, Nicholas, \& Williams, 2010). More importantly, a central issue for teacher preparation programs is the extent to which these pre-existing beliefs are viewed as flexible, i.e. responsive to the interventions of pre-service training (Yuan \& Lee, 2014). While a considerable number of researchers have argued for their inflexibility (e.g. Kagan, 1992), other researchers have found empirical evidence maintaining the inevitability of student teachers' belief change through multiple processes (Cabaroglu \& Roberts, 2000). In this respect, not only is the content of teachers' deeply grounded beliefs an important consideration, but the processes through which belief change occurs during the practicum may be a more accurate indication of an effective teacher preparation program (Borg, 2009).

The study, therefore, examined the beliefs of five student teachers about their roles as EFL (English as a Foreign Language) teachers before the practicum, and whether their perceptions about their roles changed during this experience at Qatari government schools. The study further explored the factors within the socio-cultural context that may have influenced the development of their beliefs, such as the availability of learning opportunities, as well as the establishment of strong relationships with the school mentor and university supervisor. As commonly described, the development of student teachers' beliefs are highly contextualized and dependent upon such factors, among others (Tang, Lee, \& 
Chun, 2012). Specifically in an Arab context, teachers have commonly adopted the traditional role of knowledge transmitters (Abu Rass, 2013; Assalahi, 2013). Therefore, the choice of the practicum experience is especially significant as student teachers have the opportunity to examine and reflect on the way their beliefs about teachers' roles influence several aspects of their teaching practices (Wan, Low, \& Li, 2011).

Although numerous studies have investigated EFL teachers' beliefs about teaching and learning (Ahonen et al., 2014; Borg, 2009), there appears to be few studies that examine teacher beliefs in reform settings, such as in Arab EFL teaching (Assalahi, 2013; Bellalem, 2015), and fewer studies that explore changes to student teachers' belief about their roles (Abu Rass, 2013). Therefore, there is a need for more knowledge about the development of student teachers' beliefs about their roles, specifically during the practicum experience. Such an investigation into Arab student teachers' perceptions of their roles will be of importance in extending the discourse on the beliefs they bring to the practicum experience and whether these beliefs undergo certain changes under the influence of socio-cultural factors.

\section{Literature Review}

\subsection{Complexity in defining teachers' beliefs}

Researchers have become increasingly interested in teachers' beliefs, emphasizing their influence on classroom practices, student learning, and professional development (Pajares, 1992). According to Kagan (1992), teacher beliefs are tacit, often unconsciously held assumptions about students, teaching, learning, and subject matter. Further, Borg (2009) considers teacher beliefs as a system comprising a set of beliefs about the general educational field and subject-specific content. More specifically, Löfström and Poom-Valickis (2013) specify teachers' beliefs as personal theories about teaching, influencing how teachers react to situations, what choices they make, and what strategies they adopt.

Despite various definitions, researchers agree upon common features characterizing these underlying assumptions. For example, it is widely accepted that teachers' beliefs about teaching and learning are often developed through the 'apprentice of observation', during the years they spend at school as students (Lortie, 1975). Thus, they are 'imbued with emotive commitment' and are consequently accepted as truths by the individual (Borg, 2001, p. 186). Furthermore, research reveals the symbiotic relationship between beliefs and practice; a relationship described as being dynamic and complex in nature (Fang, 1996). These beliefs are likely to influence the pedagogical practices adopted in the classroom, as well as teachers' participation within their professional communities (Ahonen et al., 2014). As such, researchers emphasize the personal and contextual nature of beliefs, and the role of experience in their development (Borg, 2003).

Given these features, teachers' beliefs are considered intricately complex (Pajares, 1992), and thus equally difficult to examine. Beliefs cannot simply be 
observed explicitly or measured directly, rather, they must be inferred by examining the statements teachers make about their beliefs, and their intentionality to carry out classroom practices in particular ways (Johnson, 1994).

\subsection{Teachers' beliefs about their roles}

Researchers have typically reported a wide range of roles for foreign language teachers. Wan et al. (2011) revealed teachers' roles to encompass the teacher as provider, nurturer, instructor, cultural transmitter, authority, interest arouser, and co-worker. Furthermore, Beck (2008) conceptualized four teacher roles according to teaching methods, learning approaches, teacher control, and student-teacher communication. Ranging from high to low levels of control, teachers may enact presenter, instructor, participant, or consultant roles. By way of caution, Ahonen et al., (2014) noted the possibility of teachers holding contradictory beliefs about their roles, consisting of beliefs that ranged from reproducers of knowledge to facilitators of learning.

Specifically in the Arab context, researchers have highlighted the adherence of EFL teachers to the traditional role of knowledge transmitters (Abu Rass, 2013; Assalahi, 2013). In several studies, Arab EFL teachers have been depicted as authoritarian; favoring teacher-centered methods, imposing hierarchical relationships with students, and maintaining strict discipline (Assalahi, 2013; Gulnaz, Alfaqih, \& Mashhour 2015). Even when educational reform was concerned, Arab teachers typically resisted change, mainly due to the incompatibility between their beliefs and the reform's radical transformation in curriculum and teaching methods (Ibrahim, Al Kaabi, \& El Zaatari 2013).

In a study of teachers' beliefs about their roles, Wang and Du (2016) revealed that these were defined based on how teachers planned and conducted teaching activities, what they emphasized in teaching, and how they perceived their relationships with their students and the work environment. The researchers argued that that this approach to categorizing beliefs provides a deeper understanding of the multi-faceted nature of teachers' beliefs about their roles, as well as the complexity of shaping and transforming such beliefs.

\subsection{Stability or flexibility of teacher beliefs}

In formal teacher preparation, student teachers' professional learning begins from a set of deeply held beliefs about teaching and learning (Borg, 2003; Pajares, 1992), acquired from their previous experiences as learners (Mattheoudakis, 2007). While some researchers assert the stability of teachers' beliefs (Çapan, 2014; Tang et al., 2012), a large number of studies contend their flexibility and predisposition towards change (Cabaroglu \& Roberts, 2000; Busch, 2010; Yuan \& Lee 2014), making the influence of teacher preparation programs on belief change a controversial issue.

In interpreting the stability of teachers' beliefs, researchers argue that teachers' pre-existing beliefs serve to filter new knowledge and skills acquired during their teacher education before they are assimilated into existing schemata (Johnson, 1994). As a result, what teachers learn from their university experience 
is heavily influenced by these perceptions (Ng et al., 2010). Specifically when teachers' pre-existing beliefs are incompatible with those introduced through university coursework, changes in their beliefs and consequently practices do not occur (Nettle, 1998). This view would constitute a major challenge for teacher preparation programs as it questions their value in effecting belief change (Cabaroglu \& Roberts, 2000).

The practicum experience may also have a low impact on the development of teachers' beliefs due to hindering factors within the school context (Mattheoudakis, 2007; Le Huu Nghia \& Ngoc Tai, 2017). For one, the high demands of teaching may overwhelm student teachers and their attention may divert towards routine tasks, classroom management, and lesson preparation, resulting in few opportunities for reflection (Moore, 2003). Further, at the heart of the practicum lies the relationship between student teachers and their mentors (Gan, 2014). It is often suggested that student teachers rarely question their mentors' teaching practices (Nguyen, 2019). Consequently, subtle power relations with their mentors might hinder student teachers' belief development, specifically when mentors exert considerable control over their practices (Yuan \& Lee, 2014).

This 'stability' view has been brought under scrutiny. According to sociocultural perspectives, belief change may be effected through teachers' participation within social settings and interaction with culturally constructed artifacts, such as the prescribed curriculum and established policies (Yuan \& Lee, 2014). Under the supervision of their mentors, student teachers can be assisted in enhancing their reflective abilities, including their ability to think about their experiences, analyze their beliefs in relation to these experiences, and consider alternatives for action (Abu Rass, 2014). The potential of reflective practice lies in developing student teachers' personal beliefs about their roles and enabling the transfer of what they have learned from their university courses into the classroom, resulting in the transformation of theory into practice (Korthagen, 2010).

In sum, student teachers' learning environments include various socio-cultural factors that may support or challenge their professional learning and belief change. Consequently, Cabaroglu and Roberts (2003) emphasize that belief change is "variable, cumulative and evolutionary" (p. 398), such that the failure to detect changes in beliefs towards those promoted by the university experience should not exclude the possibility of belief change in different directions. The findings of their study revealed a range of belief change categories, including awareness, consolidation, elaboration, addition, reordering, relabeling, linking up, disagreement, reversal, pseudo change, and no change.

Informed by Wang and Du's (2016) conceptualization of teachers' roles and Cabaroglu and Roberts' (2000) framework on teacher belief change, this study examined EFL student teachers' beliefs about their roles during their teaching practicum. The findings were intended to generate useful implications for the way teacher belief change can be supported in teacher preparation programs. Specifically, the following research questions guided the study: 
1- How do student teachers perceive their roles as EFL teachers prior to the practicum experience in Qatari government school?

2- How do student teachers' beliefs about their roles change during the teaching practicum experience in Qatari government schools?

\section{Methodology}

3.1 Context and participants

The study was situated in the context of the EFL teacher preparation program at a large university in Qatar. The four-year program includes a range of language and general education courses. As the only teacher preparation program in the country, the program aims to graduate a cohort of novice teachers capable of adhering to the professional standards for teachers set forth by the Qatari Ministry of Education and Higher Education.

Towards the end of the program, student teachers were engaged in a ten-week practicum experience at Qatari government schools, during which they worked collaboratively with their assigned mentors, who become responsible for guiding and evaluating them at the schools. Throughout the ten weeks, student teachers carried out numerous tasks, which increased gradually until they became completely responsible for student learning by the end of week four. Through weekly seminars, university supervisors played an important role in providing student teachers with opportunities to construct meaningful understandings of effective language teaching.

Enrolled in their final semester before graduation, five female student teachers from the same cohort participated in this study. The program tends to attract a majority of female student teachers, with very few male students. Through a convenience sampling technique, these student teachers were selected for two reasons: First, they were the only cohort of EFL student teachers graduating that year. Second, they conducted their teaching practicum at the same preparatory school (grades 7-9), thus allowing an in-depth investigation of their belief change under the influence of the same socio-cultural factors. Participants had different backgrounds, including Yemeni, Qatari, Pakistani, and Bahraini nationalities. They were all in their early twenties and had learned English as a foreign language through their educational experiences in Arabic speaking schools in Qatar, beginning in grade four.

\subsection{Data collection}

The investigation involved a qualitative research methodology entailing multiple data-generation methods (Creswell, 2009). The exploratory nature of the study enabled an in-depth focus on the experiences of the participants in the context of the teaching practicum. Pre- and post-interviews, weekly journals, and mid- and post-reflective essays were chosen as data gathering techniques because they could provide an authentic understanding about participants' evolving beliefs. Collecting data from multiple sources was used to triangulate insights into participants' beliefs about their roles. As the participants were enrolled in the EFL program, all data sources were written in English, as were the interviews conducted in English as well. Participants were also encouraged to speak in Arabic during the interviews as long as they expressed their 
thoughts clearly and completely. The authors worked as instructors at the teacher preparation program, and participants had taken several courses with two of them in the early stages of their program.

During the pre-interview, participants described their thoughts on language teaching and learning, the roles of teachers, their relationships with students, and effective teaching strategies. Particular emphasis was placed on their previous experiences as English language learners at school. The post-interview tapped into the same understanding of teachers' roles and responsibilities towards student learning. Further questions on participants' perceptions of their role change, the factors influencing such change, and the benefits of the practicum experience were added. The face-to-face interviews were audiotaped and transcribed directly after the interview took place.

On a weekly basis, participants kept a written journal. These weekly journals were kept open-ended; meaning participants were encouraged to write about any highlights from their week, such as challenges, learning moments, or meaningful interactions with others. Participants were required to submit these journals via email before they attended the weekly seminars.

For the mid- and post-reflective essays, participants wrote about their experiences in response to a set of questions that structured their reflections. The questions prompted the participants to reflect upon their roles, their students' roles, and the characteristics of a good teacher. Sample questions included: How do you see your role as an English language teacher? What instructional strategies should teachers use to help students learn English? They were further prompted to describe the challenges they had faced, and specify the kind of support they further needed. Participants were required to submit the midreflective essays after completing week five of the practicum experience and the post-reflective essays at the end of the practicum experience.

\subsection{Data analysis}

Prior to analysis, the data collected from each participant was organized in chronological order within the same document. This allowed tracking participants' evolving beliefs about their roles according to the time of data collection. The data collected from the various sources were analyzed using the constant comparative model (Denzin \& Lincoln, 1998). This involved an iterative process of coding and recording participants' perceptions of their roles onto a separate spreadsheet, namely completed by the authors who were not supervising the participants during the practicum. Throughout the cyclical process, two levels of coding were undertaken: First, any descriptive quotations, written responses, or reflections related to participants' beliefs about their roles or the socio-cultural factors influencing changes in beliefs were coded respectively.

Following this step, the isolated segments of data were organized according to Wang and Du's (2016) conceptualization of teachers' beliefs about their roles, which included the following categories: a) how student teachers planned and taught, b) what they emphasized in teaching, and c) how they interacted with 
others, including students and mentors. During the second round of analysis, the data were recoded and categorized according to the type of teacher role inferred following previous studies in the field (Wan et al., 2011; Beck, 2008; Ahonen et al., 2014). Finally, the categories emerging from this process were compared across the five cases to look for emerging thematic patterns on the development of their beliefs, according to Cabaroglu and Roberts' (2000) study. Thus, the processes of belief change categories, whether awareness, consolidation, elaboration, addition, reordering, relabeling, linking up, disagreement, reversal, or pseudo change, were used to describe the process of change occurring in the student teachers' beliefs. The presentation of the findings in the next section includes data from all sources. Specifically, interview data were provided to triangulate the results of the journals and essays, as well as give voice to the participants as they perceptualized their beliefs about their roles.

\section{Findings}

The finding presented below were organized around three themes following Wang and Du (2016): How student teachers carried out teaching to facilitate students' learning, what they wanted to teach and achieve, and how they perceived their relationships with their students and mentors.

\subsection{Student teachers' beliefs about their roles prior to the practicum}

How they planned to teach prior to the practicum

The results indicated that the participants held three main beliefs about their roles as future teachers. First, the teacher as provider role emphasized the accuracy of the knowledge that the teacher should possess and how to send this information to the students' (P3). In this regard, they discussed making the material easier, presenting lessons in an engaging way, and providing multiple opportunities for learning through examples and (re)explanations. Throughout the lesson, as one participant emphasized: 'I have to keep tracking the students, not they are depending on themselves' (P3).

Second, the teacher as facilitator role represented participants' beliefs in the centrality of students' roles compared to that of the teacher. Participants planned to use deductive methods of teaching, implement cooperative learning techniques, and incorporate different strategies. To this end, participants believed that understanding students' abilities was the first step in planning lessons that would engage their learners as active participants. As one participant stated:

"My role depends on me understanding my student's abilities, background, learn more about their dreams or what they face in everyday, that can help me guide them toward achieving their goals"

The comparison between these two roles was irrelevant to the participants, as they did not consider them contradictory in nature. For instance, they discussed involving students in sharing their preferred activities, yet at the same time, they 'decide what is best for all the students' (P5). One participant further explained 
this discrepancy:

"I will give them the knowledge, but not all the knowledge because they must search for it, they must work for the knowledge so they have a comprehension" (P2)

Finally, the teacher as authority role was stressed by three participants, who expressed their concern about controlling students from the first day. Their description of a good student entailed paying attention, following instructions, and respecting the teacher. The role of the teacher was to establish a 'strong hold over the class, so they can respect you and don't do anything bad' (P4).

What they wanted to achieve prior to the practicum

The way in which teachers referred to their roles in developing students' language skills emphasized two areas of competency: a focus on form and a focus on meaning. To achieve these goals, participants discussed two main roles consistent with the goals pursued.

Through a focus on form, participants highlighted the importance of teaching grammar for language proficiency. To achieve this goal, their role of teacher as provider was considered necessary. Participants discussed exposing their students to step-by-step procedures, showing correct language usage, and providing drill-and-practice exercises. Participant 4, for example, was discontent with the English textbooks because they did not include enough 'information about grammar'.

To achieve a focus on meaning, three participants described a contradictory role to the teacher as provider; that of teacher as participant. Assuming this role, participants wanted their students to become fluent speakers by learning 'in the natural way' (P2), which meant stressing the similarities between the first and second language, engaging students in role play, and exposing students to a variety of authentic resources. Their preferred method to enhance students' communication skills was inquiry-based learning. Through this method, students would be encouraged to develop their ability to ask questions, search for information, and think critically. As participants in the learning process, teachers would also 'discuss and share their information' with students, and 'keep an important thing in her mind that she is also learning from her students' (P5).

How they wanted to interact with others prior to the practicum

Participants agreed that having good relationships with students and their mentors would help them become better teachers. However, they defined different roles in relation to these two groups.

To most participants, the teacher as nurturer was a common role. They valued 'being friendly with students' (P3), 'caring for them' (P5) and 'understanding their needs' (P2). To this end, the teacher should make it her aim to 'know her students, their likes, and dislikes' in order to create lessons that 'connect to them' (P2). Accordingly, participants believed that students would respond positively 
in a class where they felt safe to share ideas openly. Additionally, participants saw themselves in the role of teacher as interest arouser. They believed it was the teacher's responsibility to motivate learners and attract their attention through engaging and purposeful activities. As described by one participant, a teacher 'must be creative, making the lesson engaging, grabbing their attention, and making them leaving the class and looking forward for the next class' (P2).

In relation to their mentors, the student teachers accepted the teacher as apprentice role quite readily. They were willing to follow through with their mentor's instructions and do whatever she requested, 'because she have the experience' (P4). They anticipated establishing close relationships with their mentor to make the most of their practicum experience. As one participant stated: 'My plan is now I have to meet my mentor and I have to be nice with her, that's it' (P3).

\subsection{Changes in student teachers' beliefs about their role during the practicum}

How they planned and taught during the practicum

During the practicum, participants' beliefs about their roles underwent several changes in regards to how they planned and taught lessons. For instance, the teacher as facilitator role was replaced with the teacher as instructor role, in the sense that the teacher made the decisions during the lesson planning phase, and then closely guided students through different activities. Participants were concerned about following the lesson plan 'in each step as possible as I can' (P4) and became frustrated when things did not go as planned. Their focus became on time management and how they struggled to 'stick to the time frame for every part of the lesson plan' (P3), until they were finally successful.

Frequently, participants maintained the teacher as provider role, though expanding this role beyond grammar instruction only. Commonly, this role entailed explaining the grammatical rule, answering the exercises in the textbook, and checking the answer from the CD. Several reasons were given to justify their reliance upon this traditional role. For instance, participants realized that their students' English levels were surprisingly low and that they did not use English to communicate in class. Participants further realized the obligation to complete the exercises in the textbooks, which imposed a presenter-like teaching style. Participant 5 described her struggle with teaching grammar as follows:

"Teaching a grammar lesson was quite challenging for me...I faced that problem due to the low level of some of the students and one of the students asked me that she didn't understand the rule and I tried to repeat it in simpler way and it was the same. In that case I tried to explain it in Arabic."

The teacher as authority role was further consolidated, with all the participants believing in the importance of this role in accomplishing other roles. In fact, one of the first observations made about the mentor was her (in)ability to control the class. For example, Participant 1's first comments about her mentor was: 'The class was very talkative and hyperactive. The teacher took more than five minutes to control the class'. In this regard, two participants linked being self- 
confident and calm with their ability to control the class. The others confirmed their prior beliefs in using warnings and punishment to control students. For example, as one participant monitored her classroom management in two classes, she concluded that 'this problem wasn't because of my teaching. It was about the students' (P3).

In addition to these general roles, participants described other roles in a more detail-oriented manner. The thematic analysis of the various sources of data resulted in additional roles to those discussed in the literature. Consequently, these roles deserve further elaboration:

Firstly, participants emphasized the teacher as technology specialist role. In all cases, participants initially believed technology would be an important tool to engage their learners and achieve their goals. Upon reflecting on this experience, they disagreed with this initial belief and considered it 'a waste of time' because 'students were not on task' (P2) and 'weren't paying attention to the instructions' (P5). More importantly was the fact that they could not complete all the steps in the lesson plan, thus deciding to limit the use of technology to that of an assessment tool.

Secondly, occupying teachers' beliefs was the role of teacher as special needs advocate, thus adding to their repertoire of teacher's roles. Upon realizing the different levels of their students, participants 'planned to improve the situation' and 'give each student their rights in learning' (P5) by making their activities 'suitable, not for one level, but for all levels' (P1). They considered 'paying attention to different abilities' as their most important role (P2). Participants continued to refine their beliefs in the importance of differentiating instruction throughout the practicum.

A final role identified was that of teacher as problem solver. Participants described several instances when they faced challenges, causing them to feel frustrated until they found reasonable solutions. Through these problem solving acts, they refined the way they planned and taught. For example, upon noticing the difference in students' behavior during the first and last periods, Participant 1 decided to 'add some excited games or video to wake up the students in first block' and 'separate girls because groups are not suitable for last block', thus reordering the importance of her initial beliefs about implementing cooperative learning.

What they wanted to achieve during the practicum

Throughout the practicum, there remained several references to their roles in developing students' language skills in the two areas of form and meaning, with a wider range of language skills emphasized. Participants' common focus on form was maintained as they continued to discuss the importance of teaching grammar for language proficiency, as one participant explained:

"I think that grammar lessons are very important because without grammar, spoken and written words loses their meaning" (P5)

In this regard, the role of teacher as provider was emphasized at the beginning of 
the practicum. Towards the end of the practicum, participants began to realize the shortcomings of this role on student engagement and learning, even though they did not act upon this newly acquired belief. As one participant stated:

"I used the textbook to explain the grammar rule and it wasn't as useful as I thought. I realized that lecturing all the time was boring and students wouldn't concentrate." (P4)

The role of teacher as participant was rejected during the practicum, even though participants still wanted their students to become fluent speakers, as well as attentive listeners 'because listening and speaking are related' (P2). In its place, participants emphasized the role of teacher as instructor, guiding students through a range of material and supplementing the textbook with other resources.

Participants further aimed to improve students' language proficiency in reading and writing. Assuming the instructor role, participants guided their students in discussing reading passages, learning new vocabulary words, brainstorming ideas, and producing written compositions.

\section{How they interacted with others during the practicum}

A rearrangement in the importance of participants' beliefs was observed in their interactions with their students. Participants' belief in the role of teacher as nurturer received less emphasis, as they confronted 'noisy' (P3) and 'hyperactive' (P1) students, who 'talk too much without pay attention' (P4) during the first few weeks. 'Dealing with students' (P1) successfully became their major concern. In this regard, participants consolidated their belief in the role of teacher as interest arouser. They struggled to maintain their role in motivating students, specifically to minimize negative behaviors. Participants were eager to find multiple ways to keep students focused and learning, including games, videos, competitions, and rewards, as one participant explained: 'when there are varieties, this will help students learn and will help teacher in her teaching to be effective' (P1).

Through their interactions with their mentors, four participants reinforced their belief in the role of teacher as apprentice. As one participant explained: 'I am always trying to be with my mentor, to acquire as much as I can from her experience' (P1). Throughout the practicum, they accepted the mentor as a superior, who showed them 'right from wrong' (P3). They further associated their mentors' positive comments with their own improvement, as one participant stated: 'that encourage me and made me think that I am improving in creating the activities' (P3). In addition to teaching activities, these participants depended heavily on their mentors for advice on controlling disruptive students. They imitated their mentor's actions and 'took her advice as a rule that I should follow through my teaching journey' (P5).

Unlike her peers, one participant's beliefs in the role of teacher as apprentice gradually changed through her interactions with the mentor. During the first few weeks, Participant 2 accepted this role, as she described the way her mentor 
taught her 'some very interesting things'. However, their relationship began to take a different direction as she realized the conflicts in their beliefs. For example, her mentor 'always insists on the textbook', yet she wanted to 'get away little by little from the textbooks and gather resources from different places' (P2). She adopted the role of teacher as learner, critically thinking about her mentor's comments and deciding on future actions, as she explained: 'I tried my best to follow my instinct' (P2).

\section{Discussion}

The current study has aimed to examine five student teachers' beliefs about their roles, and the potential change of these beliefs as they completed their practicum experience. Analysis of multiple sources of qualitative data were reported in the aspects of how teachers plan, what they aim to achieve, and how they interact with others in the school community, following the structure suggested by Wang and $\mathrm{Du}$ (2016).

Similar to the findings in Yuan and Lee (2014), several interrelated change processes were detected in the way participants planned and taught lessons. First, upon realizing students' low proficiency levels and their obligation towards the textbook, they strengthened their beliefs in the role of teacher as provider. Second, as participants struggled with time management, they rejected the anticipated teacher as facilitator role and adopted the role of teacher as instructor. Third, all participants realized the importance of the teacher as authority role and insisted on controlling their classes. While two participants associated being self-confident and calm with their ability to maintain control over the class, three participants consolidated their prior beliefs in using warnings and punishments.

These roles resemble those suggested by Wan et al. (2011). Yet, other roles were further elaborated within participants' belief repertoire, thus expanding the adopted theoretical framework through uncovering additional teacher roles. For instance, more nuanced understandings of their roles were acquired on the field, thus constituting an addition to their belief repertoire. While initially accepting the role of teacher as technology specialist, participants disagreed with this belief upon realizing the way technology hindered lesson completion. Further, upon realizing the different levels of students, participants adopted the role of teacher as special needs advocate. Lastly, participants polished their teaching practices as they faced and solved several problems, thus emphasizing the importance of the teacher as problem solver role.

Given the open-ended nature of the weekly journals, participants seemed to reflect more on the way they had planned and taught and less on the language goals they wanted to achieve. Nevertheless, there remained several references to their roles compatible with the language skills targeted. Through a focus on form, participants consolidated the role of teacher as provider, despite realizing its shortcomings on student engagement and learning towards the end of the practicum. Participants' focus on language form echoes EFL teachers' beliefs about grammar teaching in Arab culture as suggested by Assalahi (2013), as well 
as in other EFL settings (Sato \& Oyanedel, 2019). Further, participants rejected the role of teacher as participant in achieving a focus on meaning. Instead, they adopted the role of teacher as instructor and guided their students in developing language skills through a structured set of activities.

Examining the way student teachers interacted with their students and mentors revealed several changes in their beliefs. While there was an initial emphasis on the role of teacher as nurturer before the practicum, a rearrangement in the importance of participants' beliefs was observed as they confronted the realities of the classroom. In line with previous research (Gao \& Benson, 2012; Nguyen, 2019), student teachers struggled with discipline issues and thus became more concerned about their role in motivating students and designing various activities to keep them engaged, leading to the consolidation of the role of teacher as interest arouser (Wan et al., 2011). Above all, participants' beliefs about their roles were influenced by their interactions with the mentor. Before the practicum, participants were concerned about establishing strong relationships with their mentors and consequently accepted the role of teacher as apprentice. During the practicum, the mentors were described as supporting lesson planning and classroom teaching. In this regard, four participants adopted the methods of the mentor, regardless of whether they conflicted with their own personal beliefs (Moore, 2003; Nguyen, 2019). Only one participant rejected this passive role, thinking critically about her mentor's recommendations before accepting or rejecting them.

Using Cabaroglu and Roberts' (2000) framework, the results of the current study showed the flexibility of student teachers' beliefs, including varied processes of change occurring throughout the practicum. As discussed, these change processes included: awareness, consolidation, elaboration, addition, re-ordering, linking-up, and disagreement. While Cabaroglu and Robert (2000) identify discrete categories for belief change, this study extended their findings by showing the interrelated nature of change, such that realization may lead to consolidation, which may further lead to linking-up beliefs. As a result, different belief change processes have occurred depending mainly on student teachers' individual experiences and their encounters with the socio-cultural context (Gan, 2014; Yuan and Lee, 2014), thus contributing to the development of an intricate belief system, which may continue to guide their teaching methods, goals and social interactions.

Notwithstanding the importance of the flexibility of student teachers' beliefs for professional learning and development (Mattheoudakis, 2007), the results of the current study have revealed the divergence between the student teachers' anticipated roles, which were described before the practicum, and their actual roles, which were enacted during the practicum. As a consequence, participants were unsuccessful in achieving their projected goals, specifically those pertaining to their beliefs in the advantage of the teacher's roles as facilitators, participants and nurturers. According to Tang et al. (2012), changes to student teachers' beliefs necessitates the acquisition of an intricate belief system aligned with the teachings of university courses and translated into actual practices 
during the practicum. With this definition of change in mind, the debate concerning the flexibility or stability of teacher beliefs becomes of secondary importance in comparison to whether changes in beliefs lead to the desired goals of the teacher preparation program.

\section{Implications and Conclusion}

The findings in this study have questioned the debate about whether student teachers' beliefs can be considered flexible or stable. In line with previous research (Gan, 2014; Yuan and Lee, 2014), the study demonstrated the development of student teachers' beliefs through multiple processes described in Cabaroglu and Roberts's (2000) study. Despite the short duration of the practicum experience, the student teacher' initial beliefs underwent subtle changes about their roles as future teachers. However, student teachers' belief change towards the goals of their teacher preparation program were not always achieved. Accordingly, desired change in beliefs may require the implementation of several conscientious recommendations.

Given the situated nature of the practicum experience, several socio-cultural factors played an influential role in the development of student teachers' beliefs. Quite commonly, participants documented their engagement in multiple social learning activities, such as classroom observations, collective planning sessions, and professional development. They were able to try out new ideas, build a repertoire of time and management skills, and develop strategies to overcome challenges (Le Huu Nghia \& Ngoc Tai, 2017; Tang et al., 2014). Through the establishment of closer partnerships between universities and schools, student teachers may further engage in a variety of field experiences. However caution should be taken when choosing partner schools, as the context "must be able to offer a sound balance between safety and challenge" (Korthagen, 2010, p. 419).

Throughout the practicum, student teachers engaged in reflective practices about their learning experiences with their university supervisor during weekly seminars. In line with previous research (Wang \& Du, 2016), such reflections contributed to the development of the student teachers' beliefs about their roles. Therefore, it is recommended that university supervisors acknowledge on-site learning opportunities and take part in maximizing their impact by engaging their students in open discussions and structured reflections while further acknowledging the time required for such reflections to influence belief change (Abu Rass, 2013).

Third, despite the importance of these learning activities, student teachers appeared to be occupied with several procedural concerns, such as time management and discipline issues. Once on the field, student teachers reflected upon their lived experiences, with less thought given to the general goals of their practices, acquired through their university coursework. As a result, the changes occurring in their beliefs about their roles were not always aligned with their university teachings, resulting in a gap between student teachers' learning during the practicum and their experiences at the university (Korthagen, 2010). It may be necessary to engage student teachers in examining the theoretical 
constructs behind their pedagogical decisions, instead of focusing on procedural concerns (Moore, 2003). Members at the school and the university need to move together beyond simply reporting student teachers' practices, to inquiring into the thinking and decision-making that dictate such practices.

Another important factor within the school context constituted the relationship between the student teachers and their mentors. In line with previous research (Gan, 2014; Nguyen, 2019; Yuan, 2016), the student teachers in this study willingly approved the superiority of their mentor's role, "rather than risk disapproval" (Moore, 2003, p. 40). This may have been an expected outcome, given the fact that the mentors participated in evaluating the student teachers' performance. Unexpectedly, one participant was able to critically consider her mentor's recommendations, specifically when they clashed with her personal belief system. It is recommended that members of the university community play a more active role in raising awareness of the subtle power relationships between mentors and their mentees, while ensuring that their students manage the integration into the school community successfully. Given the powerful impact of the mentor on the processes of student teachers' belief change (Yuan \& Lee, 2014), it may be important to further examine whether their classroom practices are compatible with the theoretical underpinnings presented at the university setting to avoid the presence of conflicting demands upon student teachers.

To conclude, although the study included a small number of participants and as such may have limitations as to how the results can be generalized, it nonetheless highlighted the intricate nature of student teachers' beliefs about their roles and the processes of belief change. In this respect, the dichotomy between the stability of student teachers' beliefs and their flexibility was undermined. Instead, facilitating student teachers' belief change towards the goals of the teacher preparation program as well as those they had anticipated for themselves emerged as a pressing need. In this way, the critical goal of preparing teachers capable of performing multiple roles to facilitate student learning and participate as active learners in the field requires further investigation. Further research can also investigate the long-term belief change of student teachers particularly during their first few years as language teachers in an EFL context. As the socio-cultural context presents both challenge and opportunity, it would be meaningful to further explore the way different contexts influence the multiple processes of student teachers' belief change.

\section{References}

Abu Rass, R. (2013). Conceptual change among Arab student teachers. Journal of Education and Learning, 2(1), 189-196. https//dx.doi.org/10.5539/jel.v2n1p189

Abu Rass, R. (2014). Developing reflective skills among EFL student teachers. International Journal of English Language Teaching, 2(3), 1-14.

Ahonen, E., Pyhältö, K., Pietarinen, J., \& Soini, T. (2014). Teachers' professional beliefs about their roles and the pupils' roles in the school. Teacher Development, 18(2), 177-197. https / / dx.doi.org/10.1080/13664530.2014.900818

Assalahi, H. M. (2013). Why Is the Grammar-translation Method Still Alive in the Arab World? Teachers. Beliefs and Its implications for EFL Teacher Education. Theory 
and Practice in Language Studies, 3(4), 589-599. https//dx.doi.org/10.4304/tpls.3.4.589-599

Beck, S. (2008). The teacher's role and approaches in a knowledge society. Cambridge Journal of Education, 38(4), 465-481. https://doi.org/10.1080/03057640802482330

Bellalem, F. (2015). The study of foreign language teachers' beliefs: implications for research in the Arab world. English Lingua Journal, 1(1), 91-106.

Borg, M. (2001). Teachers' beliefs. ELT Journal, 55(2), 186-188. https://doi.org/10.1093/elt/55.2.186

Borg, S. (2009). Language teacher cognition. In A. Burns \& J. C. Richards (Eds.), The Cambridge Guide to Second Language Teacher Education (pp. 163-171). New York: Cambridge University Press.

Brewer, D. J., Augustine, C. H., Zellman, G. L., Ryan, G. W., Goldman, C. A., Stasz, C., \& Constant, L. (2007). Education for a new era: Design and implementation of k-12 education reform in Qatar. Rand Corp: Santa Monica, CA. Retrieved May 17, 2017 from https://www.rand.org/pubs/monographs/MG548/.

Busch, D. (2010). Pre-service teacher beliefs about language learning: The second language acquisition course as an agent for change. Language Teaching Research, 14(3), 318-337. https://doi.org/10.1177/1362168810365239

Cabaroglu, N., \& Roberts, J. (2000). Development in student teachers' pre-existing beliefs during a 1-year PGCE programme. System, 28, 387-402. https://doi.org/10.1016/S0346251X(00)00019-1

Çapan, S. A. (2014). Pre-service English as a Foreign language teachers' belief development about grammar instruction. Australian Journal of Teacher Education, 39(12), 131-152.

Creswell, J. (2009). Research Design: Qualitative, Quantitative, and Mixed Methods Approaches (3rd Ed.). Thousands Oaks, CA: Sage.

Darling-Hammond, L. (2010). Evaluating Teacher Effectiveness: How Teacher Performance Assessments Can Measure and Improve Teaching. Center for American Progress: Washington, DC.

Denzin, N. K, \& Lincoln, Y. S. (1998). Collecting and Interpreting Qualitative Materials. California: SAGE.

Fang, Z. (1996). A review of research on teacher beliefs and practices. Educational Researcher, 38, 47-64. https://doi.org/10.1080/0013188960380104

Gao, X., \& Benson, P. (2012). 'Unruly pupils' in pre-service English language teachers' teaching practicum experiences. Journal of Education for Teaching, 38(2), 127-140. https://doi.org/10.1080/02607476.2012.656440

Gan, Z. (2014). Learning from interpersonal interactions during the practicum: A case study of non-native ESL student teachers. Journal of Education for Teaching, 40(2), 128-139. https:/ / doi.org/10.1080/02607476.2013.869969

Garrido, C., \& Alvarez, I. (2006). Language teacher education for intercultural understanding. European Journal of Teacher Education, 29(2), 163-179. https://doi.org/10.1080/02619760600617342

Gulnaz, F., Alfaqih, A. M., \& Mashhour, N. A. (2015). Paradigm shift: a critical appraisal of traditional and innovative roles of an English teacher in Saudi ELT classrooms. Theory and Practice in Language Studies, 5(5), 934-946. https://dx.doi.org/10.17507/tpls.0505.07

Ibrahim, A., Al Kaabi, A., \& El Zaatari, W. (2013). Teacher resistance to educational change in the United Arab Emirates. International Journal of Research Studies in Education, 2(3), 25-36.

Johnson, K. E. (1994). The emerging beliefs and instructional practices of preservice 
English as a second language teachers. Teaching and Teacher Education, 10(4), 439452. https://doi.org/10.1016/0742-051X(94)90024-8

Kagan, D.M. (1992). Implication of research on teacher belief. Educational Psychologist, 27(1), 65-90. https://doi.org/10.1207/s15326985ep2701_6

Korthagen, F. (2010). How Teacher Education Can Make a Difference. Journal of Education for Teaching, 36(4), 407-423. https:// doi.org/10.1080/02607476.2010.513854

Le Huu Nghia, T., \& Ngoc Tai, H. (2017). Preservice Teachers' Identity Development during the Teaching Internship. Australian Journal of Teacher Education, 42(8). http://dx.doi.org/10.14221/ajte.2017v42n8.1

Löfström, E., \& Poom-Valickis, K. (2013). Beliefs about teaching: Persistent or malleable? A longitudinal study of prospective student teachers' beliefs. Teaching and Teacher Education, 35, 104-113. https://doi.org/10.1016/j.tate.2013.06.004

Lortie, D.C. (1975). School Teacher: A Sociological Study. University of Chicago, Chicago.

Mattheoudakis, M. (2007). Tracking changes in pre-service EFL teacher beliefs in Greece: A longitudinal study. Teaching and Teacher Education, 23(8), 1272-1288. https://doi.org/10.1016/j.tate.2006.06.001

Moore, R. (2003). Reexamining the field experiences of preservice teachers. Journal of Teacher Education, 54(1), 31-42. https://doi.org/10.1177/0022487102238656

Morrison, B. R., \& Navarro, D. (2012). Shifting roles: From language teachers to learning advisors. System, 40(3), 349-359. https://doi.org/10.1016/j.system.2012.07.004

$\mathrm{Ng}$, W., Nicholas, H., \& Williams, A. (2010). School experience influences on pre-service teachers' evolving beliefs about effective teaching. Teaching and Teacher Education, 26(2), 278-289. https://doi.org/10.1016/j.tate.2009.03.010

Nguyen, M. H. (2019). Mentoring in professional experience: A source of tensions and emotions. In M. H. Nguyen (Ed.), English Language Teacher Education (pp. 105126). Singapore: Springer.

Pajeres, M. (1992). Teachers' beliefs and educational research: Cleaning up a messy construct. Review of Educational Research, 62(3), 307-332. https://doi.org/10.2307/1170741

Sato, M., \& Oyanedel, J. C. (2019). "I think that is a better way to teach but ...": EFL teachers' conflicting beliefs about grammar teaching. System, 84, 110-122. https:// doi.org/10.1016/j.system.2019.06.005

Tang, E. L. Y., Lee, J. C. K., \& Chun, C. K. W. (2012). Development of teaching beliefs and the focus of change in the process of pre-service ESL teacher education. Australian Journal of Teacher Education, 37(5), 90-107.

Wan, W., Low, G. D., \& Li, M. (2011). From students' and teachers' perspectives: Metaphor analysis of beliefs about EFL teachers' roles. System, 39(3), 403-415. https://doi.org/10.1016/j.system.2011.07.012

Wang, L., \& Du, X. (2016). Chinese language teachers' beliefs about their roles in the Danish context. System, 61, 1-11. https://dx.doi.org/10.1016/j.system.2016.06.009

Yuan, E. R. (2016). The dark side of mentoring on pre-service language teachers' identity formation. Teaching and Teacher Education, 55, 188-197. https://doi.org/10.1016/j.tate.2016.01.012

Yuan, E. R., \& Lee, I. (2014). Pre-service teachers' changing beliefs in the teaching practicum: Three cases in an EFL context. System, 44, 1-12. https://doi.org/10.1016/j.system.2014.02.002 